\title{
Perbandingan Keefektifan Adjuvan Inhalasi Lidokain Dengan Spray Lidokain Sebagai Obat Anestetik Lokal Pada Pasien Endoskopi Saluran Cerna Atas
}

\author{
Aldy Heriwardito ${ }^{1 *}$, Eddy Harijanto ${ }^{1}$, Tauhid Asri Utomo ${ }^{1}$ \\ 1. Departemen Anestesiologi dan Terapi Intensif, Fakultas Kedokteran Universitas Indonesia, \\ RSUPN Dr. Cipto Mangunkusumo, Jakarta, Indonesia
}

\begin{abstract}
ABSTRAK
Latar Belakang: Teknik multimodal analgesia dengan menggunakan dua atau lebih obat analgesik yang berkerja pemeriksaan endoskopi saluran cerna merupakan prosedur untuk mengevaluasi berbagai gejala saluran pencernaan, namun sering ditolak pasien karena menimbulkan efek samping nyeri dan rasa tidak nyaman karena gag reflex. Penggunaan adjuvan inhalasi lidokain sebagai obat anestetik lokal dapat menurunkan angka kejadian gag reflex sehingga dapat menjadi pilihan untuk sedasi pada endoskopi saluran cerna atas. Penelitian ini bertujuan untuk membandingkan keefektifan dari spray lidokain dan inhalasi lidokain sebagai adjuvan pada endoskopi saluran cerna atas.

Metode: Penelitian ini menggunakan metode uji klinis acak tersamar tunggal pada 150 pasien yang menjalani endoskopi saluran cerna atas dengan sedasi di RSUPN Cipto Mangunkusumo. Pasien dibagi menjadi dua kelompok sama besar untuk adjuvan inhalasi yang berbeda. Sebanyak 75 orang pada kelompok pertama diberikan $0,5 \mathrm{mg} / \mathrm{kgBB}$ spray lidokain sedangkan 75 orang pada kelompok kedua diberikan 1,5 mg/kgBB inhalasi lidokain. Penilaian efek sedasi diukur menggunakan Skala Sedasi Ramsay. Data yang terkumpul dianalisis secara statistik.

Hasil: Gag reflex terjadi sebanyak 1,3\% dari total subjek pada kelompok inhalasi lidokain dan 30,7\% subjek pada kelompok spray lidokain $(\mathrm{P}<0,001)$. Rerata rescue dose propofol yang didapatkan pada kelompok inhalasi lidokain adalah $0,67 \pm 5,77 \mathrm{mg} / \mathrm{kgBB}$ dan pada kelompok spray lidokain adalah $11 \pm 17,9 \mathrm{mg} / \mathrm{kgBB}(\mathrm{P}<0,001)$.

Simpulan: Inhalasi lidokain lebih efektif sebagai anestetik lokal dibandingkan spray lidokain sebagai adjuvan pada endoskopi saluran cerna atas.
\end{abstract}

Kata Kunci: Endoskopi saluran cerna atas, gag reflex, inhalasi lidokain, spray lidokain 


\title{
MACC Lomparison Between Nebulized Lidocaine and Spray Lidocaine as
}

\author{
Aldy Heriwardito ${ }^{1 *}$, Eddy Harijanto ${ }^{1}$, Tauhid Asri Utomo ${ }^{1}$
}

1. Departement of Anesthesiology and Intensif Care, Faculty of Medicine, Universitas Indonesia, Dr. Cipto Mangunkusumo National General Hospital, Jakarta, Indonesia

\begin{abstract}
Background: Gastrointestinal endoscopy is a procedure to evaluate various gastrointestinal symptoms, but oftenly rejected by patients because of the side effects and discomfort due to the gag reflex. The use of lidocaine inhalation adjuvan as a local anesthetic drug can reduce the incidence of gag reflex, and could be an option for sedation in upper gastrointestinal endoscopy. This study aimed to compare the effectiveness of lidocaine spray and lidocaine inhalation as an adjuvan in upper gastrointestinal endoscopy.

Methods: This study was a single blind randomized clinical trial in 150 patients who underwent upper gastrointestinal endoscopy under sedation at Cipto Mangunkusumo National General Hospital. Patients were randomized into two groups, lidocaine spray group and lidocaine inhalation group. Seventy-five people in the first group were given $5 \mathrm{mg} / \mathrm{kgBW}$ of lidocaine spray, seventy-five people in the second group were given $1.5 \mathrm{mg} / \mathrm{kgBW}$ of lidocaine inhalation. The sedation effect was assessed using the Ramsay Sedation Scale. Collected data were statistically analyzed.

Results: Gag reflex occurred in 1.3\% subjects in lidocaine inhalation group and $30.7 \%$ subjects in lidocaine spray group $(P<0.001)$. Mean rescue dose of propofol in lidocaine inhalation group was $0.67 \pm 5.77 \mathrm{mg} / \mathrm{kgBW}$ and in lidocaine spray group was $11 \pm 17.9 \mathrm{mg} / \mathrm{kgBW}(P<0.001)$.

Conclusion: Nebulized lidocaine is more effective as local anesthetic than spray lidocaine for adjuvan in upper gastrointestinal endoscopy.
\end{abstract}

Keywords: upper gastrointestinal endoscopy, gag reflex, nebulized lidocaine, lidocaine spray 


\section{PENDAHULUAN}

Nyeri didefinisikan sebagai suatu pengalaman endoskopi saluran cerna atas merupakan prosedur untuk mengevaluasi berbagai gejala saluran pencernaan dengan melakukan visualisasi secara langsung kelainan di mukosa saluran cerna. ${ }^{1}$ Pemeriksaan ini relatif aman, namun sering ditolak pasien karena menimbulkan efek samping nyeri dan rasa tidak nyaman yang disebabkan oleh gag reflex..$^{1,2}$

Prosedur endoskopi saluran cerna sudah rutin dikerjakan menggunakan sedasi dan analgesia intravena. Tujuan dari sedasi dan analgesia adalah untuk mengurangi kecemasan dan ketidaknyamanan pasien, meningkatkan kualitas dari hasil endoskopi, dan mengurangi ingatan pasien terhadap tindakan endoskopi. ${ }^{3}$

Pemberian anestesi topikal dan/atau sedasi juga dapat diberikan untuk mengurangi risiko gag reflex. Tingkat sedasi harus dicapai secara titrasi agar aman, nyaman, dan tindakan endoskopi dapat berjalan lancar. Setiap pasien memiliki respons berbeda terhadap sedasi, sehingga memerlukan tingkat sedasi yang berbeda untuk prosedur yang sama dan tiap pasien dapat mencapai tingkat sedasi yang berbeda dalam satu prosedur. ${ }^{3}$ Obat yang biasa digunakan adalah benzodiazepine, seperti midazolam dan diazepam, yang dapat diberikan tunggal atau dikombinasikan dengan golongan opioid. Midazolam lebih sering digunakan karena onsetnya lebih cepat, durasi kerjanya pendek, dan adanya efek amnesia. Opioid yang dapat digunakan adalah meperidine dan fentanyl. ${ }^{3,4}$

Penggunaan propofol sebagai obat sedasi selama endoskopi saluran cerna atas sudah banyak digunakan. Sedasi dengan propofol dinilai lebih efektif dan dengan masa pemulihan yang lebih cepat dibandingkan sedasi biasa dengan midazolam dan opioid. Namun penggunaan propofol sebagai obat sedasi dapat memberikan beberapa efek samping, antara lain yang sering terjadi saat dilakukan induksi adalah turunnya tekanan darah arteri. Pada pasien tanpa masalah jantung, dosis induksi propofol 2-2,5 mg/kgBB dapat menurunkan tekanan darah sistolik 25-40\%. Pada dosis induksi, propofol dapat menyebabkan terjadinya apnea pada $25-30 \%$ pasien. Untuk mencegah kejadian hipotensi pada pasien yang memiliki masalah jantung, dapat diberikan cairan intravena terlebih dahulu sesuai kebutuhan pasien dan pemberian propofol secara titrasi untuk mencapai tingkat sedasi yang diinginkan. ${ }^{5}$ Penelitian yang dilakukan oleh Hanhart dkk. menyatakan bahwa pemberian adjuvan anestesi lidokain topikal pada pasien endoskopi saluran cerna atas sebelum dilakukan induksi dengan propofol dapat menurunkan angka kejadian gag reflex. ${ }^{6}$ Lidokain merupakan obat anestesi lokal yang digunakan secara luas baik melalui pemberian topikal maupun intravena. Lidokain dapat diberikan secara topikal sebagai gel, inhalasi, maupun dalam bentuk spray lidokain yang terdiri dari beberapa konsentrasi, diantaranya $2 \%, 4 \%$, dan $10 \%$. Obat ini diindikasikan untuk menghasilkan rasa baal sementara saat dilakukan pemeriksaan seperti bronkoskopi maupun endoskopi. Selain itu, lidokain juga dapat menghilangkan refleks batuk dan muntah. ${ }^{7-10}$

Inhalasi lidokain merupakan pilihan alternatif untuk anestesi lokal. Proses nebulisasinya dapat membuat lidokain sampai ke dinding posterior faring lebih merata dibandingkan pemberian dengan jelly atau spray. Cara nebulisasi dapat memecah partikel zat aktif menjadi ukuran yang sangat kecil sekitar $5 \mu \mathrm{m}$, dengan nebulizer pasien hanya bernafas biasa sambil menghirup uap nebul yang mengandung obat anestesi..$^{7-10}$

Penelitian bertujuan untuk mengetahui perbandingan keefektifan inhalasi lidokain dan spray lidokain sebagai adjuvan propofol pada pasien yang menjalani prosedur endoskopi saluran cerna bagian atas.

\section{METODOLOGI PENELITIAN Desain Penelitian}

Penelitian ini merupakan uji klinis acak tersamar tunggal dan bersifat eksperimental untuk membandingkan keefektifan inhalasi lidokain dengan spray lidokain dan lidokain inhalasi sebagai adjuvan propofol pada pasien endoskopi saluran cerna bagian atas. Besar sampel yang diambil sebanyak 150 subjek dan telah mendapat persetujuan dari Komite Etik Fakultas Kedokteran Universitas Indonesia. Sampel kemudian dibagi menjadi 2 kelompok, yaitu kelompok spray lidokain (75 subjek) dan inhalasi lidokain (75 subjek). Penelitian ini dilakukan pada bulan November - April 2018 di 
ruang Pusat Endoskopi dan Saluran Cerna (PESC) RSUPN Cipto Mangunkusumo.

\section{Kriteria Inklusi dan Eksklusi}

Pasien yang dijadwalkan untuk prosedur endoskopi saluran cerna akan dievaluasi kelayakannya untuk diikutsertakan dalam penelitian. Kriteria inklusi penelitian ini adalah pasien berusia 18-60 tahun, indeks massa tubuh (IMT) 18,5 - 29,9, status ASA I dan II, bersedia ikut serta dalam penelitian, dan menandatangani informed consent. Kriteria eksklusi penelitian ini adalah pasien dengan riwayat alergi, memiliki kontraindikasi penggunaan propofol dan/atau lidokain, pasien dengan penurunan kesadaran, pasien dengan hemodinamik tidak stabil, pasien dengan luka terbuka pada mukosa mulut dan lidah, serta pasien dengan kemungkinan sulit dilakukan ventilasi dan intubasi.

\section{Protokol Penelitian}

Pasien yang dijadwalkan untuk prosedur endoskopi saluran cerna dan sesuai dengan kriteria penerimaan dan tidak masuk kriteria penolakan, dilakukan informed consent tertulis. Kemudian dilakukan randomisasi secara komputerisasi. Pencatatan data pasien meliputi nama, usia, jenis kelamin, berat badan, tinggi badan, dan indeks massa tubuh (IMT). Dilakukan pemasangan monitor elektrokardiogram, tensimeter, saturasi oksigen, dan pemasangan kanulasi intravena 22G. Data awal hemodinamik pasien yang dicatat meliputi: tekanan darah, saturasi oksigen, dan frekuensi nadi.

Pasien yang akan menjalani prosedur endoskopi digolongkan menjadi 2 kelompok penelitian dan diberikan 2 adjuvan propofol yang berbeda yaitu kelompok inhalasi lidokain dan kelompok spray lidokain.

Pada pasien kelompok spray lidokain diberikan inhalasi dengan plasebo, pemberian spray lidokain dilakukan 3-5 menit sebelum dilakukan endoskopi. Pemberian dilakukan secara berkala pada dasar lidah, area peritonsil, dan palatum. Dosis lidokain spray yang digunakan untuk setiap pasien adalah $1,5 \mathrm{mg} / \mathrm{kgBB}$. Hasil penghitungan dosis ini akan dilakukan pembulatan keatas jika $>5$ dan pembulatan ke bawah jika $<5$. Pasien lalu diminta melaporkan bila telah merasakan baal pada rongga mulut.
Pada pasien kelompok inhalasi lidokain pemberian inhalasi dilakukan 3-5 menit sebelum dilakukan endoskopi. Masker nebulizer disambungkan ke sumber oksigen sentral dan dialirkan sebesar $7 \mathrm{lpm}$. Dosis lidokain inhalasi yang digunakan untuk setiap pasien adalah $1,5 \mathrm{mg} / \mathrm{kgBB}$. Hasil penghitungan dosis ini akan dilakukan pembulatan ke atas jika $>5$ dan pembulatan ke bawah jika $<5$. Pasien lalu diminta melaporkan bila telah merasakan baal pada rongga mulut. Pencatatan dan pengawasan akan dilakukan oleh residen anestesi yang bertugas di PESC sementara pemberian anestesi lokal dilakukan oleh peneliti.

Pasien lalu dipasang mouth gag dan nasal kanul 2-4 liter/menit. Pasien diberikan bolus fentanyl 1 $\mathrm{mcg} / \mathrm{kg}$, tunggu hingga 3 menit. Pasien diberikan bolus propofol 1,5 mg/kgBB sesuai protokol. Untuk rumatan pasien akan diberikan propofol intravena kontinu dengan syringe pump dosis sedasi $25-75 \mathrm{mcg} / \mathrm{kgBB}$.

Tingkat sedasi diukur dengan Ramsay sedation scale (RSS), dengan target sedasi RSS 4-5. ${ }^{11}$ Setelah pasien mencapai tingkat sedasi yang cukup, operator dipersilakan untuk memulai tindakan. Dilakukan monitor rutin tekanan darah, laju nadi, laju napas, saturasi oksigen, dan RSS tiap 5 menit. Apabila terjadi gag reflex, peningkatan tekanan darah, dan/atau laju nadi lebih dari $20 \%$, atau RSS $<4$ maka dapat dilakukan bolus propofol $0,3 \mathrm{mg} / \mathrm{kgBB}$ titrasi setiap 1 menit hingga tercapai level RSS 4-5. Apabila terjadi hipotensi dilakukan pencatatan data dan diberikan bolus efedrin 5-15 mg IV, bila belum teratasi maka dilakukan pemasangan obat vasopresor, dan tindakan dihentikan sementara. Apabila terjadi desaturasi, dilakukan pencatatan data dan dilakukan triple airway maneuver, serta meningkatkan suplementasi oksigen. Bila belum teratasi, dapat dilakukan ventilasi tekanan positif.

Pencatatan total pemakaian propofol dan durasi tindakan dilakukan setelah prosedur endoskopi selesai dilakukan. Pasien dipindahkan ke ruang pemulihan. Selama di ruang pemulihan, dilakukan pemantauan keadaan hemodinamik serta tingkat kesadaran pasien. Pasien diperbolehkan kembali ke ruang perawatan setelah skor Aldrete 9-10. 


\section{Analisis Statistik}

Data yang telah diperoleh kemudian dianalisis dengan menggunakan program komputer Statistical Package for Social Sciences (SPSS) versi 20. Data kategorik disajikan dalam bentuk jumlah dan presentase ( $\mathrm{n}(\%))$. Data numerik disajikan dalam bentuk rerata \pm simpang baku bila sebaran data normal atau dalam bentuk median (nilai minimum-maksimum) bila sebaran tidak normal. Uji T tidak berpasangan dan uji Mann-Whitney digunakan untuk menganalisis dua variabel numerik. Hasil analisis dianggap bermakna bila nilai $p<0,05$.

\section{HASIL PENELITIAN}

Penelitian ini mengikutsertakan 150 subjek penelitian selama bulan November - April 2018. Subjek dibagi menjadi 2 kelompok, yaitu kelompok spray lidokain (75 pasien) dan inhalasi lidokain (75 pasien). Karakteristik subjek penelitian dipaparkan dalam Tabel 1.

Persentase perbandingan kejadian gag reflex pada pasien yang menjalani prosedur endoskopi saluran cerna atas dipaparkan pada Tabel 2.

Persentase perbandingan rerata tambahan rescue dose propofol pada pasien yang diberikan inhalasi lidokain dan spray lidokain dipaparkan dalam Tabel 3.

Jumlah kejadian gag reflex pada kelompok inhalasi lidokain sebesar 1 orang, dan membutuhkan penambahan rescue dose propofol sebanyak 3 kali, yaitu $1 \mathrm{mg} / \mathrm{kgBB}$. Pada kelompok spray lidokain jumlah kejadian gag reflex sebesar 23 orang, dengan angka median $0,6 \mathrm{mg} / \mathrm{kgBB}(0,27-0,96)$.

Tabel 1. Karakteristik Subjek Penelitian

\begin{tabular}{llll}
\hline Karakteristik & Inhalasi Lidokain & Spray Lidokain & Nilai P \\
\hline $\begin{array}{l}\text { Usia (tahun)* } \\
\text { Jenis Kelamin } \\
\quad \text { Laki-laki }\end{array}$ & $50(18-60)$ & $52(23-60)$ & $0,177+$ \\
$\quad$ Perempuan & $45(60 \%)$ & $42(33 \%))$ & $0,620^{*}$ \\
Kategori ASA & $30(40 \%)$ & $33(44 \%)$ & \\
$\quad$ ASA I & $3(4 \%)$ & $42(33 \%))$ & $0,467^{*}$ \\
$\quad$ ASA II & $72(96 \%)$ & $33(44 \%)$ & \\
Berat Badan (kg) & $57(35-115)$ & $56(32-115)$ & $0,876+$ \\
IMT (kg/m²) & $21,64(14,76-38,87)$ & $21,64(11,75-40,26)$ & $0,819+$ \\
Durasi Tindakan (menit) & $8(2-15)$ & $8(3-16)$ & $0,633+$ \\
Pelaku Endoskopi & & & \\
$\quad$ Konsultan & $50(50,5 \%)$ & $49(49,5 \%)$ & $0,863^{*}$ \\
$\quad$ Trainee & $25(49 \%)$ & $26(51 \%)$ & \\
\hline
\end{tabular}

*Uji Chi-square

+ Uji Mann-Whitney 


\section{PEMBAHASAN}

\section{Karakteristik Subjek}

Subjek penelitian adalah pasien yang menjalani endoskopi saluran cerna atas di Pusat Endoskopi Saluran Cerna (PESC) RSCM yang memenuhi kriteria penerimaan. Jumlah pasien adalah 150 orang. Data demografik yang menjadi karakteristik pasien dalam penelitian ini adalah jenis kelamin, usia, berat badan, indeks masa tubuh, dan status fisik pasien menurut klasifikasi dari American Society of Anesthesiologist, serta ditambahkan lama tindakan endoskopi yang dilakukan.

Perbandingan usia kedua kelompok perlakuan ini hampir sama, 50 tahun (18-60) pada kelompok inhalasi dan 52 tahun (23-60) pada kelompok

Tabel 2. Kejadian Gag Reflex pada Endoskopi Saluran Cerna Atas

\begin{tabular}{llll}
\hline \multicolumn{1}{c}{ Kejadian Gag Reflex } & \multicolumn{1}{c}{$\begin{array}{c}\text { Kelompok } \\
\text { Inhalasi Lidokain }\end{array}$} & $\begin{array}{c}\text { Kelompok } \\
\text { Spray Lidokain }\end{array}$ & Nilai P \\
\hline Ada & $1(1,3 \%)$ & $23(30,7 \%)$ & \\
Tidak Ada & $74(98,7 \%)$ & $52(69,3 \%)$ & $<0,001^{*}$ \\
Total & $75(100 \%)$ & $75(100 \%)$ & \\
\hline
\end{tabular}

* Uji Chi Square

Tabel 3. Rerata Rescue Dose Propofol

\begin{tabular}{llll}
\hline Kelompok Perlakuan & $\begin{array}{l}\text { Rata-rata Rescue } \\
\text { Dose Propofol } \pm \text { SB }\end{array}$ & $\begin{array}{l}\text { Median Rescue Dose } \\
\text { (Min-Maks) }\end{array}$ & Nilai P \\
\hline Inhalasi Lidokain & $0,67 \pm 5,77$ & $0(0-50)$ & $<0,001^{*}$ \\
Spray Lidokain & $11 \pm 17,9$ & $0(0-60)$ & \\
\hline
\end{tabular}

* Uji Mann-Whitney

spray. Pada usia $>60$ tahun membutuhkan dosis induksi yang lebih kecil (25-50\%) karena volume distribusi kecil penurunan kecepatan bersihan propofol, sedangkan pada anak-anak dosis induksi yang dibutuhkan lebih besar, karena volume distribusi yang besar dan bersihan propofol yang cepat.

Kategori ASA adalah penilaian status fisik pasien yang lazim digunakan oleh anestesi. Pada penelitian ini dikumpulkan pasien yang memiliki kategori ASA I dan II untuk meminimalkan faktor bias terkait beratnya kondisi pasien yang nantinya dapat memengaruhi dosis penggunaan propofol. ${ }^{4}$ Lama tindakan dapat memengaruhi risiko terjadinya gag reflex pada tindakan endoskopi terkait lamanya kerja obat anestetik topikal. Pada penelitian ini tidak didapatkan perbedaan rata-rata waktu tindakan, yakni 8 menit (2-13) pada kelompok inhalasi lidokain dan 8 menit (3-16) pada spray lidokain, sehingga lama tindakan dapat disingkirkan sebagai penyebab gag reflex. Karakteristik demografis kedua kelompok sebanding dan dapat dianalisis secara statistik.

\section{Endoskopi Saluran Cerna Atas}

Endoskopi saluran cerna atas merupakan prosedur yang sering dikerjakan untuk diagnostik atau terapi. Prosedur endoskopi saluran cerna atas dilakukan dengan posisi pasien miring ke kiri. Alat endoskopi akan masuk melalui faring, esofagus, lambung hingga ke duodenum dan akan visualisasi langsung apabila terdapat kelainan di mukosa saluran cerna. Endoskopi saluran cerna atas dapat digunakan untuk mengevaluasi berbagai gejala saluran pencernaan seperti nyeri 
perut, perdarahan, disfagia, odinofagia, refluks gastroesofagus, peradangan, ulkus, dan tumor. Prosedur ini sering menimbulkan efek samping nyeri dan rasa tidak nyaman yang disebabkan oleh gag reflex. ${ }^{1,2}$

\section{Lidokain}

Lidokain (Xylocaine/Lignocaine) adalah obat anestesi lokal yang digunakan secara luas baik melalui pemberian secara topikal sebagai gel, spray, maupun terapi inhalasi. Lidokain memiliki awitan yang cepat dan lama kerja sedang, yaitu 1-2 jam. Lidokain dapat menimbulkan blok yang reversibel terhadap konduksi impuls saraf pusat dan perifer setelah anestesi regional. Spray lidokain terdiri dari beberapa konsentrasi, diantaranya $2 \%, 4 \%$, dan $10 \%$. Obat ini diindikasikan untuk menghasilkan rasa baal sementara saat dilakukan pemeriksaan seperti bronkoskopi maupun endoskopi, selain itu lidokain juga dapat menghilangkan refleks batuk dan muntah. ${ }^{8,9}$

Inhalasi lidokain merupakan pilihan alternatif untuk anestesi lokal. Proses nebulisasinya dapat membuat lidokain sampai ke dinding posterior faring dan hidung secara lebih merata dibandingkan pemberian dengan jelly atau spray. Cara nebulisasi dapat memecah partikel zat aktif menjadi ukuran yang sangat kecil sekitar $5 \mu \mathrm{m}$ dan pasien dapat bernapas biasa sambil menghirup uap inhalasi yang mengandung obat anestesi. Pemberian lidokain secara inhalasi hanya akan memberikan efek topikal pada saluran nafas. ${ }^{9,10}$

Lidokain mempunyai efek samping yang minimal terhadap jantung dan jarang menyebabkan aritmia. Efek samping utamanya adalah gangguan terhadap susunan saraf pusat baik eksitasi (gugup, tremor, tinitus, pusing, pandangan kabur, dan kejang), maupun depresi (penurunan kesadaran, depresi napas, dan apnea). Apabila kadar plasma lidokain dijaga tidak melebihi 9 $\mathrm{mg} / \mathrm{L}$, efek lidokain mampu ditoleransi dengan baik oleh tubuh. ${ }^{8}$

\section{Kejadian Gag Reflex dan Rerata Tambahan Rescue Dose Propofol}

Gag reflex merupakan respons normal dari tubuh sebagai mekanisme fisiologis, yang diartikan sebagai kontraksi yang tidak disadari dari otot palatum atau faring yang menimbulkan muntah. Gag reflex merupakan refleks untuk melindungi jalan nafas dan mengeluarkan iritan dari orofaring bagian posterior dan saluran cerna bagian atas. Berdasarkan penyebab, gag reflex dapat dibedakan menjadi 2 tipe, yaitu psikologis dan somatis. Psikologis dapat berhubungan dengan kecemasan, rasa takut, visual, penciuman, dan pendengaran. Pada gag reflex karena somatis biasanya dikarenakan stimulus lokal pada area tenggorokan. ${ }^{2}$ Pelaksanaan prosedur endoskopi saluran cerna atas dapat menyebabkan stimulus lokal pada area tenggorokan yang menimbulkan gag reflex.

Lidokain inhalasi telah terbukti bermanfaat pada beberapa tindakan seperti bronkoskopi, kultur di area bronkial tanpa komplikasi dan tidak menimbulkan ketidaknyamanan bagi pasien. ${ }^{10}$ Walaupun lidokain memiliki kadar yang sangat rendah di dalam darah karena nebulisasi ini, tetapi secara sistemik dapat mengurangi nyeri. Nebulisasi lidokain dapat secara efisien menekan gag reflex, refleks batuk, dan menimbulkan anestesi pada saluran nafas. ${ }^{10}$ Pada penelitian Groeben dkk. menyatakan bahwa lidokain $4 \%$ dengan dosis $2 \mathrm{mg} / \mathrm{kgBB}$ merupakan anestesi topikal yang baik, dapat menghasilkan pengurangan hyper-reactivity dari bronkus, dan menyebabkan iritasi jalan nafas yang minimal. ${ }^{12}$ Penelitian Soenarto dkk. telah membuktikan bahwa perubahan hemodinamik selama tindakan laringoskopi dan intubasi lebih kecil pada pasien yang diberikan inhalasi lidokain dengan dosis $1,5 \mathrm{mg} / \mathrm{kgBB}^{13}$

Pada kelompok spray lidokain terdapat 23 kejadian gag reflex dari total 75 subjek, sehingga penambahan rescue dose propofol diperlukan pada pasien ini. Pada kelompok inhalasi lidokain hanya ditemukan 1 kejadian gag reflex dari total 75 subjek. Hal ini mungkin disebabkan karena keterbatasan dari penggunaan spray lidokain penyebarannya hanya ke daerah lidah dan pangkal lidah tergantung pada arah semprotan yang dilakukan. Semprotan di daerah pangkal lidah harus merata kearah kanan, kiri, serta pita suara dan trakea bagian proksimal dibawah pita suara. ${ }^{7}$ Nebulisasi dapat memecah partikel zat aktif menjadi ukuran yang sangat kecil sekitar $5 \mu \mathrm{m}$. Partikel yang kecil dan proses inhalasi selama 10 menit dapat membuat penyebaran 
obat lebih merata. ${ }^{8,9}$

Pada penelitian ini rerata rescue dose propofol lebih rendah pada kelompok inhalasi. Jumlah rescue dose yang digunakan pada 1 kejadian gag reflex pada kelompok inhalasi lidokain cukup besar, tetapi belum ada penjelasan lebih lanjut mengenai hal ini.

Penggunaan inhalasi lidokain lebih efektif dibandingkan spray lidokain, namun terdapat kekurangan pada pemakaiannya, yaitu biaya yang harus ditambahkan untuk menyediakan obat lidokain dan masker nebulizer yang digunakan. Proses nebulisasi menambah waktu persiapan sebelum tindakan endoskopi, karena proses nebulisasi dapat berjalan hingga 10 menit. $^{14,15}$

\section{Keterbatasan Penelitian}

Pada penelitian ini terdapat beberapa keterbatasan, diantaranya adalah tidak dilakukannya penilaian kepuasan pasien dan pelaku endoskopi pada kedua kelompok. Tingkat kepuasan pasien merupakan salah satu faktor penting dalam prosedur endoskopi saluran cerna atas. Hal ini berpengaruh pada kepatuhan pasien untuk menjalankan tindakan endoskopi ulang untuk evaluasi. Penelitian ini juga tidak menghitung kadar lidokain di dalam darah pada kedua kelompok. Hal ini perlu dilakukan karena lidokain inhalasi dapat terdeposit di sepanjang saluran nafas bagian atas.

\section{SIMPULAN}

Inhalasi lidokain lebih efektif dibandingkan spray lidokain dalam mengurangi gag reflex dan rescue dose propofol pada pasien endoskopi saluran cerna atas. Kejadian gag reflex pada kelompok inhalasi lidokain lebih sedikit dibandingkan kelompok spray lidokain pada pasien endoskopi saluran cerna atas. Rerata rescue dose propofol pada kelompok inhalasi lidokain lebih kecil dibandingkan kelompok spray lidokain pada pasien endoskopi saluran cerna atas.

\section{DAFTAR PUSTAKA}

1. Boyer J, Prat F, Abitbol V, Apiou R, Czernichow $P$, Guyot H. Guidelines departement. Diagnostic indications for upper gastrointestinal endoscopy in oesophageal and gastroduodenal disease in adults, excluding endoscopic ultrasonography and enteroscopy [disitasi tanggal 18 April 2017]. Tersedia dari https://www.has-sante.fr/.

2. Bassi GS, Humphris GM, Longman LP. The etiology and management of gagging: $A$ review of the literature. J Prosthet Dent. 2004; 91(5): 459-67.

3. Lichtenstein $D R$, Jagannath $S$, Baron $T H$, Anderson MA, Banerjee S, Dominitz JA, et al. Sedation and anesthesia in gastrointestinal endoscopy. Gastrointest Endosc. 2008;68(5):

4. Chang YT, Tsai TC, Hsu H, Chen YM, Chi $K P$, Peng SY. Sedation for gastrointestinal endoscopy with the application of targetcontrolled infusion. Turk J Gastroenterol. 2015; 26(5): 417-22.

5. Ghallab M, Hussien RM, Samir GM, Ibrahim DA. Palatal lidocaine gel as an adjuvan to propofol only for sedation during upper gastrointstinal tract endoscopy: a comparative study. Ain-Shams J Anesthesiol. 2014; 7(4): 524-9.

6. Çam H, Pehlivan S, Dağ MS, Yılmaz N, Demir U, Gülşen MT. Study of ideal topical pharyngeal anesthesia in upper gastrointestinal system endoscopy: A double-blind, randomized, controlled trial. Turk J Gastroenterol. 2016; 27(2): 103-7

7. Trevisani L, Sartori S, Gaudenzi P, Gilli G, Matarese G, Gullini S, et al. Upper gastrointestinal endoscopy: Are preparatory interventions or conscious sedation effective? A randomized trial. World J Gastroenterol. 2004; 10(22): 3313-7.

8. Spektor M, Kaplan JL, Kelley J, Dalsey W. Nebulized or sprayed lidocaine as anesthesia for nasogastric intubation. Acad Emerg Med. 2000; 7(4): 406-8.

9. Noitasaeng $P, \quad$ Vichitvejpaisal $P$, Kaosombatwattana $U$, Jaiyen $T$, Siriwongsa S. Comparison of spraying and nebulized lidocaine in patients undergoing esophagogastro-duodenoscopy: A randomized trial. J Med Assoc Thai. 2016; 99(5): 462-8

10. Groeben H, Growendt T, Silvanus M, Beste $M$, Peters J. Lidocaine inhalation for local anaesthesia and attenuation of bronchial hyper-reactivity with least airway irritation. Effect of three different dose regimens. Eur J 
Anaesthesiol. 2000; 35(6): 672-9

11. Laurenza C, Mattei A, Antonelli S, Capiello D, Carassiti M. Evaluation of sedation for the unconscious patient: are we still far away? J Anesth Crit Care Open Access. 2014; 1(2): 1-10.

12. Groeben $H$, Growendt T, Silvanus M, Beste $M$, Peters J. Lidocaine inhalation for local anaesthesia and attenuation of bronchial hyper-reactivity with least airway irritation. Effect of three different dose regimens. Eur J Anaesthesiol. 2000; 35(6): 672-9

13. Soenarto RF, Pryambodho, Puspitasari R. Farmakologi opioid. Buku ajar anestesiologi. Jakarta: Departemen Anestesiologi dan Intensive Care Fakultas Kedokteran
Universitas Indonesia/ RS Cipto Mangunkusumo. 2012; 2(9): 149-75.

14. Sudarto, Soeroso NN, Hasibuan P, Eyanoer PC. Perbandingan kenyamanan pasien yang menjalani prosedur anestesi lokal secara spray dengan nebulisasi pada pemeriksaan bronkoskopi serat optic lentur. J Respir Indo. 2015; 35(2): 72-7.

15. Perdana A, Kapuangan C, Adinugroho P. Perbandingan keefektifan gel lidokain $2 \%$ dengan spray lidokain $10 \%$ untuk mengurangi dosis propofol pada pasien endoskopi saluran cerna atas. Program Studi Anestesiologi dan Terapi Intensif Fakultas Kedokteran Universitas Indonesia. 2015. 